\title{
How Households Adjust their Consumption and Investment Plans under Longevity Risk: An Experimental Approach-based Study in Taiwan
}

\author{
Joseph J. Tien and Jerry C.Y. Miao \\ Department of Insurance, Tamkang University, Ying-Chuan Rd., Tamsui, Taipei County 251, Taiwan. \\ E-mails: jilltien@mail.tku.edu.tw; cymiao@mail.tku.edu.tw
}

\begin{abstract}
Longevity risk may be defined as the risk of outliving one's accumulated wealth. Although many theoretical studies have suggested that individuals will increase their precautionary saving in order to mitigate longevity risk, only a few of such studies have used empirical data to test people's decision-making behaviour in response to longevity risk. The main purpose of this paper is to investigate how households adjust their consumption and investment plans in response to longevity risk. We find that households reduce their consumption over their entire lifespan and increase the proportion of their risky assets before retirement when they face longevity risk. Furthermore, we also discover that households with females, more children, higher health expenditure and greater risk aversion change their risky assets to a lesser extent in their whole life period in the face of longevity risk, compared with other households.
\end{abstract}

The Geneva Papers (2013) 38, 803-823. doi:10.1057/gpp.2013.22

Keywords: longevity risk; consumption decisions; investment decision; ageing society

Article submitted 14 April 2012; accepted 11 June 2013; published online October 2013

\section{Introduction}

In the last two decades, with improvements in the quality of life, the health of the environment and medical technology, average human life expectancy has significantly increased. An ageing population is becoming a serious issue that needs to be recognised and managed in almost every country. As in many countries, ageing is a serious problem in Taiwan because of the prolonged lifespan and low fertility of its population. According to the statistics from the Taiwan government, the aged population was about 2.49 million at the end of 2010, accounting for 10.74 per cent of Taiwan's total population. This percentage is predicted to double to 20 per cent by 2026 and to 40 per cent by $2050 .{ }^{1}$ Moreover, according to a survey conducted by the Population Reference Bureau, Taiwan had the world's lowest fertility rate in 2009 and 2010, with an average of one child per woman. Thus, investigating an individual's behaviour under longevity risk in Taiwan has become an important issue.

\footnotetext{
${ }^{1}$ Taiwan Council of Economic Planning and Development (2008).
} 
804

Longevity risk may be understood as existing at both aggregate and individual levels. ${ }^{2}$ As pointed out by MacMinn et al., ${ }^{3}$ methods for dealing with longevity risk have become an important topic for many interested parties, including governments, life insurers and individuals. Many studies have also investigated how to alleviate longevity risk in the capital market at the aggregate level. At the individual level, individuals may be aware of longevity risk and, if so, this awareness may influence their decision-making behaviour. The issues relating to the decisions individuals make when facing longevity risk appear to have gained recognition and importance in the literature. Theoretical studies have suggested that longevity risk plays an important role in individuals' decisions about consumption and saving, ${ }^{4}$ retirement timing ${ }^{5}$ and asset allocation. ${ }^{6}$ This paper focuses on the longevity risk issue at the individual level. Its purpose is to investigate, through a questionnaire and an experiment with assumed scenario conditions, how households adjust their consumption and investment plans in the face of longevity risk.

Modigliani and Brumberg and Modigliani and Ando ${ }^{7}$ have developed the "life-cycle hypothesis", which states that households tend to maintain a steady expenditure over their entire lifespan. Then, Modigliani ${ }^{8}$ points out that savings should be positive for households during their working life and negative during retirement; thus, a chart of savings over time would be bell-shaped. Moreover, some scholars have used the "habit formation" theory, according to which an individual's past consumption might influence the utility of current consumption. ${ }^{9}$ In other words, "habit formation" implies that it is difficult for individuals to change their consumption behaviour significantly. However, some studies disagree with the "habit formation" theory and argue instead that when people become aware of longevity risk, they will reduce their expenditure and increase their precautionary saving. ${ }^{4}$ Thus, the issue of how people adjust their consumption plans in response to longevity risk remains a controversial one that needs to be investigated further. Some of the theoretical studies relating to the asset allocation decisions of individuals over time have shown that the risk asset holding is independent of both the age and wealth of an individual under certain specific assumptions. ${ }^{10,11}$ Subsequent, studies have applied parts of these theoretical model assumptions and derived different results based on the original model. Households decrease the percentage of risky assets in their portfolio as they age if the asset returns are not followed by an independent and identical normal distribution over time. ${ }^{12}$ Furthermore, Hochguertel ${ }^{13}$ finds the share of

${ }^{2}$ MacMinn et al. (2006); Stallard (2006).

${ }^{3}$ MacMinn et al. (2006).

${ }^{4}$ Cocco and Gomes (2009); De Nardi et al. (2009).

${ }^{5}$ Cocco and Gomes (2009).

${ }^{6}$ Menoncin (2008); Milevsky et al. (2006); Schulze and Post (2010); Stevens (2010); Cheng and Han (2011); Post (2012); Yogo (2012).

${ }^{7}$ Modigliani and Brumberg (1954); Modigliani and Ando (1957).

${ }^{8}$ Modigliani (1986).

${ }^{9}$ Dynan (1993); Fuhrer and Klein (2006).

${ }^{10}$ Mossin (1968); Merton (1969); Samuleson (1969).

${ }^{11}$ The theoretical result is based on the following important assumptions. Firstly, the representative agent has the constant relative risk aversion (CRRA) utility function. Secondly, asset returns are independently and identically distributed over time. Thirdly, the representative agent has no labour income or a non-tradable asset. Finally, the financial market is a frictionless and complete market.

${ }^{12}$ Kandel and Stambaugh (1996); Campbell and Viceira (1999); Barberis (2000).

${ }^{13}$ Hochguertel (2003). 
risky assets to total wealth to be hump-shaped over the working lifetime, assuming income uncertainty, liquidity constraints and precautionary saving behaviour. With respect to investment decision under longevity risk, Yang and Huang ${ }^{14}$ document that individuals will include more risky assets in their portfolio during the annuity accumulation period to mitigate the longevity risk. Thus, based on the above theoretical literature, we predict that households may adjust their risky asset holding in response to longevity risk.

Although previous scholars have provided evidence on decision-making behaviour in relation to longevity risk based on theoretical models, ${ }^{15}$ relatively few studies have used empirical data to investigate this issue, partly because of the lack of detailed data. Most previous empirical studies support a strong negative relationship between the age and the percentage of risky assets in the portfolio. ${ }^{16}$ By using cross-sectional data, Yoo ${ }^{17}$ finds that the ratio of risky assets to wealth increases over the individual's working life, and then declines after retirement. Furthermore, Post and Hanewald ${ }^{18}$ provide the first empirical evidence within the growing theoretical literature that analyses individual decision-making under longevity risk. In this paper, we use a questionnaire-based experimental methodology to investigate how households adjust their decisions under longevity risk. Our paper contributes to the literature in two ways. Firstly, previous papers often examine either consumption or investment decisions concerning a change in life expectancy. However, the interaction between consumption and investment should be taken into account. Secondly, finding an appropriate proxy for measuring longevity risk by using real data may be difficult. Furthermore, collecting real data over a long-term period is expensive and time-consuming. In our study, we use uncertain life extension as the proxy for the longevity risk and observe participants' decision-making behaviour in such a scenario. Thus, our usage of a questionnaire-based experimental approach in these circumstances provides an alternative method for analysing multi-dimensional plans made by households faced with longevity risk.

In our study, we invited participants who are the heads of households, are aged between 30 and 45 years and married, to indicate their consumption and investment decisions in two scenarios. In the process of collecting data, we recorded their consumption and investment plans, with and without longevity risk. We then analysed how each household's demographic characteristics affect consumption and investment plans under longevity risk. With regard to consumption plans, our empirical results show that the household will reduce their consumption significantly when they are faced with longevity risk. Our finding is consistent with the conclusions in the theoretical literature that an increase in precautionary saving could be an optimal response to longevity risk. With regard to investment decisions, we find that households intend to increase significantly the risky asset portion of their investments before retirement in response to longevity risk. This may be because they take on more risk in the expectation of higher returns, which can increase the extra money needed to pay for a longer life expectancy. However, households become more conservative towards risky asset holding after retirement even if they face longevity risk. Furthermore, our empirical results

\footnotetext{
14 Yang and Huang (2009).

15 Schulze and Post (2010).

${ }^{16}$ Bodie and Crane (1997); Heaton and Lucas (2000); Bertaut and Starr McCluer (2002).

${ }^{17}$ Yoo (1994).

${ }^{18}$ Post and Hanewald (2013).
} 
also indicate that households with females, more children, higher health expenditure and absolute risk aversion increase the portion of their risky asset holding to a lesser extent over their entire lifespan, compared with other households. From the above results, we find that household characteristics determine if they will actively modify their investment decisions to manage longevity risk. Our empirical findings support the conclusion that households adjust their consumption and investment plans in response to longevity risk.

The remainder of this paper is organised as follows. Longevity risk will be discussed in the next section. Then, we explain the methodology we used to investigate participant's behaviour in response to longevity risk. The latter section contains variable definitions, summary statistics and empirical results. Some discussions and implications are presented in the penultimate section. We provide our conclusions in last section.

\section{Longevity risk}

Longevity risk may be defined at an aggregate or individual level. At the aggregate level, longevity risk may be defined as the risk that the average member of a birth cohort will live beyond the normal life expectancy. At the individual level, longevity risk may be defined as the risk of outliving one's accumulated wealth. The reduction in mortality rates for older aged individuals also induces some social and economic challenges. Fertility rates have fallen in many countries and this, in conjunction with the increase of the elderly population, has caused the inversion of some countries' age distributions and increased the severity of the longevity risk problem for many government pension plans by both extending the payout period and reducing the tax base. ${ }^{3}$ Furthermore, the government has also broadened expenditure on public health insurance because of the increase in the proportion of the elderly. Life insurers also face the pressure of longevity risk. For example, in selling an annuity product to their customers, they need to account for longevity risk, that is, the risk that annuitants might live longer on average than anticipated in the life insurers' mortality tables used to price annuities. ${ }^{19}$

Both practical and theoretical solutions for alleviating longevity risk have grown increasingly in recent years. Capital markets indeed provide governments, corporations and life insurers with vehicles to hedge longevity risk more efficiently. ${ }^{20}$ Many market investors may be interested in longevity derivatives, since mortality-linked products can provide a zero-beta asset to diversify their portfolios. ${ }^{21}$ Thus, some mortality-linked products have been created by the capital market (longevity bond, 2003; q-forward contract, 2008; longevity swap, 2008). Many studies have also provided possible measurements for evaluating these longevity derivatives, for example, the pricing of longevity bonds, ${ }^{22}$ pricing of longevity-linked derivatives such as survivor swaps, ${ }^{23}$ survivor forward ${ }^{24}$ and q-forwards. ${ }^{25}$

\footnotetext{
19 Blake et al. (2006b).

${ }^{20}$ MacMinn et al. (2006); Brown and Orszag (2006).

${ }^{21}$ Blake and Burrows (2001).

22 Chen and Cummins (2010); Kogure and Kurachi (2010).

23 Dowd et al. (2006).

${ }^{24}$ Dawson et al. (2010).

${ }^{25}$ Deng et al. (2012).
} 
Although numerous studies have attempted to investigate from a macroeconomic perspective what longevity risk is and how such risk can be mitigated, other studies have also examined this issue from the individuals' perspective and concluded that longevity risk is also an important determinant in individuals' decisions. However, only a few papers discuss individuals' decision under longevity risk by using empirical data. Post and Hanewald ${ }^{18}$ show that individuals are aware of longevity risk by using a data set that matches subjective survival expectations from the Survey of Health, Ageing and Retirement in Europe (SHARE) with life table data from the Human Mortality Database. Furthermore, they find that the awareness of longevity risk translates into an increased dispersion of savings income, which indicates that disagreement effects impact the underlying decisionmaking process. To follow the path of previous studies, our paper provides more empirical evidence relating to the decision-making process in the face of longevity risk.

\section{Methodology}

\section{Process of collecting data}

We invited programmers to design the interactive experimental system on an Internet website. ${ }^{26}$ We published our recruiting information in an Internet bulletin. In order to reduce sampling error, our sample is selected based on the general population structure of Taiwan. The participants, who are the heads of households aged between 30 and 45 years old and married, were selected randomly. One participant needed to spend approximately $40 \mathrm{~min}$ to finish all the steps in our experiment. Our sample contains 112 participants. After deleting data with missing values, we kept 100 samples for use in our regression analysis.

When participants decided to take part in our experiment, they were not initially informed about exactly what this experiment would be in relation to the issue of longevity risk. They were only invited to take part in an activity relating to "economic decision-making". Therefore, self-selection depending on the type of experiment is avoided in our study. At the beginning of the experiment, we explained the rules of the activity to the participants, including how to use the interactive platform. However, in order to prevent the longevity perception affecting participants' behaviour, we did not hint at any concept of uncertain life extension until during the last round of the experiment.

After this, the participants were asked to fill in a questionnaire, with details about the characteristics of their households. This questionnaire contains three parts, pertaining to household demographics, health status perception and risk aversion. We used Eisenhauer and Ventura's ${ }^{27}$ method to measure the risk aversion of participants because their method includes a discrete theoretical model and contains only one question. This measurement can help us to estimate the risk aversion of participants quickly and precisely. All participants are asked to complete three rounds of the experiment. The first two rounds were conducted in the same conditions in order to deal with the possible learning effect during the experiment. In the first round, without longevity risk, participants make their consumption and

\footnotetext{
${ }^{26}$ Our website is on http://163.13.214.148:8080/life/index.html?method=login. The language of our interactive experimental platform is designed in Chinese.

${ }^{27}$ Eisenhauer and Ventura (2003).
} 


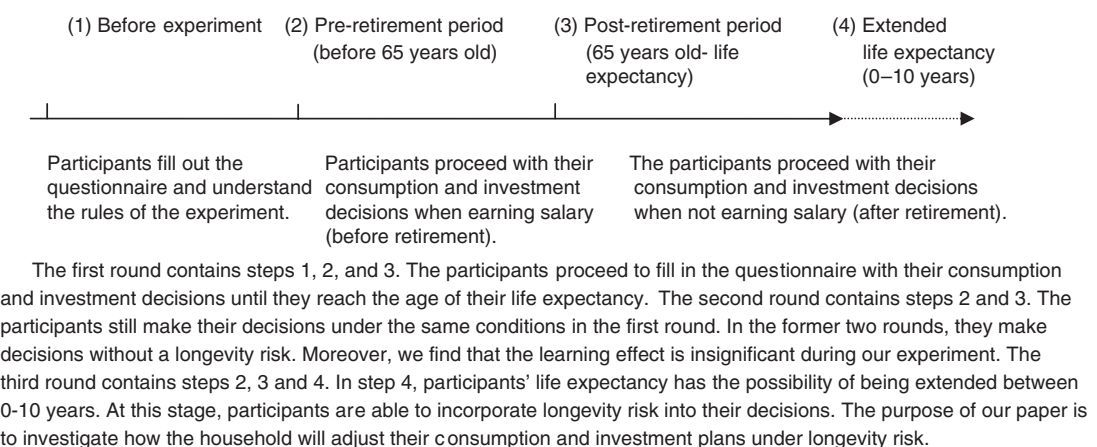

Figure 1. Experimental framework.

investment decisions based on the life expectancy they indicate in their questionnaire. ${ }^{28}$ In the second round, participants make their decisions under the same conditions as the first round. Changes in decisions between the first and the second round can be attributed to the learning effect. In order to examine whether the learning effect is significant during our experiment, we test whether the difference between the decisions in the two rounds is equal to zero or not. The empirical evidence supports the finding that the mean difference between the two rounds of decisions is not significantly different from zero and, therefore, that the learning effect is insignificant in our experiment. In the third round, participants are told that they may have an uncertain life extension for another 0-10 years, and then asked to complete their plans again. ${ }^{29}$ The only difference between the second round and the third round is a possible life extension. We use the life extension possibility as the proxy for longevity risk, and observe how the households chose to adjust their consumption and investment plans after incorporating a longevity risk into the experiment. The experimental framework is shown in Figure 1. We obtain information such as salary, net wealth and salary growth expectations from the questionnaires, and use these as data values in our experiment. ${ }^{30}$

Participants are initially asked to repeat several turns of consumption and investment decisions ${ }^{31}$ before retirement, assuming that they are 5 years older at each turn. At each turn, consumption and investment decisions are repeated with a different age, and they are given an estimated salary as income, calculated on the basis of their initial salary. At each turn, participants have to decide how much money they would spend, and then decide what percentage of their money they would invest in riskless assets and risky assets. We assume that the risk-free return is 3 per cent. The average and standard deviations of the risky asset return are 6 and 7.5 per cent, respectively. The risk-free return is publicly available information; however, the risky asset return is a random variable for all participants. (They

\footnotetext{
${ }^{28}$ People often have a prediction about how long they will live based on their perceptions about their average life, health status and hereditary disease.

${ }^{29}$ In order to avoid participant's decisions being influenced by perceptions of longevity risk, they are not informed that they will face longevity risk until they have completed all the steps during the experiment.

${ }^{30}$ The participants filled in their net wealth, monthly salary, salary growth and life expectancies in the questionnaire. We used this real information to calculate future salaries in each turn.

${ }^{31}$ In this paper, we define a series of decisions in our experiment as plans.
} 
Table 1 Number of turns per life expectancy

\begin{tabular}{lccccccc}
\hline Life Expectancy & Under 64 & $65-69$ & $70-74$ & $75-79$ & $80-84$ & $85-89$ & Over 90 \\
\hline Number of turns & 7 & 8 & 9 & 10 & 11 & 12 & 13 \\
\hline
\end{tabular}

only know the average and standard deviation of the risky asset return.) The process of wealth accumulation during the pre-retirement period is shown in Eq. (1).

$$
\begin{aligned}
& W_{t+1}=\left(W_{t}+S_{t}-C_{t}\right)\left[\alpha_{t}\left(1+r_{f}\right)+\left(1-\alpha_{t}\right)\left(1+\widetilde{r}_{t}\right)\right] \\
& t=1,2,3,4,5,6,7 \quad \text { (Pre-retirement: } 30 \text { to } 65 \text { years old }),
\end{aligned}
$$

$W_{t+1}$ and $W_{t}$ is the household wealth at turn $t+1$ and $t$, respectively. $S_{t}$ is salary at turn $t$. The questionnaire provides information regarding monthly salary and salary growth for each participant. $C_{t}$ is the consumption amount at turn $t . r_{f}$ and $\tilde{r}_{t}$ are the risk-free return and risky asset return, respectively. Each household decides how much money it will spend at the beginning of a turn. Then, the household decides what percentage $\alpha$ and $1-\alpha$ will be invested in riskless assets and risky assets, respectively (Table 1).

Participants are assumed to retire at 65 years old, after which they would no longer receive a salary. ${ }^{32}$ At assumed retirement, participants are asked to repeat the consumption and investment decision in the same manner as for the pre-retirement period. In the second round, the participants are told that they would die at the age of their life expectancy indicated in their questionnaire. For example, if a participant expects to live until 75 years old, he or she repeats the decision-making in 5-year intervals for nine turns (bringing the participant to the age of 75). This creates a situation where there is no longevity risk, as each individual could predict how long they would live. Without longevity risk, participants make their consumption and investment decisions based on their life expectancy. In the third round, participants have the opportunity to live an additional $0-2$ extra turns. ${ }^{33} \mathrm{We}$ assume the life extended probability follows the exponential function $1 /\left(1+\exp ^{\alpha}\right) .^{34}$ In other words, participants could have 0-10 years life extensions (see step 4 of Figure 1). Although the participants know they will have the chance to extend their life, they do not know the exact life extension. With longevity risk, participants make their consumption and investment

\footnotetext{
32 The pension system in Taiwan is very complicated. In order to avoid different salary amounts during postretirement period disturbing decision-making behaviour under longevity risk, we assume that there is no income after retirement.

33 One definition of longevity risk refers to the randomness around the trend in improvements of future mortality. However, in this paper, we follow definition of Blake et al. (2006a), who regard longevity risk as arising where "members of some reference population might live longer on average than anticipated". We use this definition for two reasons. Firstly, the empirical evidence generally supports the conclusion that life expectancy has been improved in past two decades (Vaupel 1986; Oeppen and Vaupel, 2002). Thus, the assumption of a longer expected lifetime in our study seems reasonable. Secondly, we find the stochastic mortality modelling assumption to be too complicated and difficult to understand by our participants. Thus, we think that the use of uncertain life extension as the proxy for longevity risk could be better than the use of the stochastic mortality assumption.

${ }^{34}$ We set alpha equal to 0.5 in our experiment. The computer will give the random life extension to each participant by this formula.
} 
decisions based on the uncertain life extension again. The process of wealth accumulation after retirement is shown in Eqs. (2) and (3).

After retirement without longevity risk

$$
\begin{aligned}
W_{t+1}= & \left(W_{t}-C_{t}\right)\left[\alpha_{t}\left(1+r_{f}\right)+\left(1-\alpha_{t}\right)\left(1+\tilde{r}_{t}\right)\right] \\
& t=8,9, \ldots, n,
\end{aligned}
$$

(Post-retirement: 65 years old to the participants' life expectancy $n$ )

After retirement with longevity risk

$$
\begin{gathered}
W_{t+1}=\left(W_{t}-C_{t}\right)\left[\alpha_{t}\left(1+r_{f}\right)+\left(1-\alpha_{t}\right)\left(1+\tilde{r}_{t}\right)\right] \\
t=8,9, \ldots, n, n+1, n+2,
\end{gathered}
$$

(To extend the participants' life expectancy between 0 and 2 additional turns)

The main difference between the two rounds is that in round 3 , the participants do not know when they will die. Thus, they could adjust their consumption and investment plans with a possible extra lifespan. We use this uncertainty in life extension as the proxy for longevity risk. As the other conditions were maintained as in the former round, we are able to observe how participants adjust their consumption and investment plans in response to longevity risk.

\section{Summary statistics and empirical results}

\section{Summary statistics}

The main purpose of this paper is to investigate how households adjust their decisions under longevity risk. Initially, participants are asked to complete a background questionnaire covering household demographics, health status perceptions and risk aversion. The demographics variables include gender, education, number of children, family salary, net wealth and bequest motivation. The variables relating to health status perceptions include the participants' life expectancy, health status and health-care expenditure. We used Eisenhauer and Ventura's ${ }^{27}$ method to measure the risk aversion of participants. Some variables including sex, age, salary, education, number of children, net wealth, life expectancy, health-care expenditure, bequest motivation and absolute risk aversion were used in regression to analyse how households with different characteristics adjust their plans in response to longevity risk. The variable definitions are described in Table 2.

Tables 3 and 4 respectively present the descriptive and quantitative statistics for our participants. In Table 3, the percentages of male and female participants are 56 and 44 per cent, respectively. The percentage of participants who graduated from university or college is approximately 57 per cent. The percentage of participants with an education level above university or college is approximately 19 per cent. Nearly 43 per cent of participants do not have any children, while 50 per cent have one or two children. This reflects the low birth rate in Taiwan. The percentages of participants who report their health status as excellent and good are 25 and 32 per cent, respectively. Nearly 38 per cent of participants consider their health status to be mediocre. The participants show that their risk attitudes are respectively 
Table 2 Variable definitions

\begin{tabular}{|c|c|c|}
\hline Variable names & Variable definitions & Abbreviation \\
\hline \multicolumn{3}{|l|}{ Demographic } \\
\hline Gender & $\begin{array}{l}\text { Gender is the dummy variable with value } 1 \text { if the head of the household is male, } \\
\text { and } 0 \text { otherwise. }\end{array}$ & Sex \\
\hline Age & Age of the respondent. & Age \\
\hline Education & $\begin{array}{l}\text { The education years of the head of the household. We translate the rank into } \\
\text { education years by the following rules. The education years are } 9,12,16 \\
\text { and } 18 \text { years if education level is, respectively, junior high school or under, } \\
\text { senior high school, university and graduated school. }\end{array}$ & $E d u$ \\
\hline Salary & The variable is the aggregate sum of the salaries of all family members. & $S$ \\
\hline Net wealth & $\begin{array}{l}\text { The net wealth is defined as the total value of the household's assets minus the } \\
\text { total value of its liabilities. }\end{array}$ & $N W$ \\
\hline Children & The variable means the number of children under 18 years old. & Chi \\
\hline $\begin{array}{l}\text { Bequest } \\
\text { motivation }\end{array}$ & $\begin{array}{l}\text { This variable means how much money the household has the willingness to left } \\
\text { to their children after parents died. }\end{array}$ & $B$ \\
\hline \multicolumn{3}{|c|}{ Health situation perception } \\
\hline Life expectancy & The participant predicts how long they will live. & $L E$ \\
\hline Health status & $\begin{array}{l}\text { The participant thinks the personal health status based on his own historical } \\
\text { medicine record. This variable can be divided into several degrees including } \\
\text { excellent, good, mediocre, illness and serious illness. }\end{array}$ & $H S$ \\
\hline $\begin{array}{l}\text { Health-care } \\
\text { expenditure }\end{array}$ & $\begin{array}{l}\text { The average amount of health-care expenditure spent by the household per } \\
\text { year. }\end{array}$ & $H E$ \\
\hline \multicolumn{3}{|l|}{ Risk attitude } \\
\hline $\begin{array}{l}\text { Absolute risk } \\
\text { aversion }\end{array}$ & $\begin{array}{l}\text { The variable is defined as the Arrow-Pratt measure of absolute risk-aversion } \\
\text { (ARA). }\end{array}$ & $A R A$ \\
\hline
\end{tabular}

risk-averse (68 per cent) and risk neutral ( 28 per cent). Only 4 per cent of the respondents are classified as risk lovers.

Table 4 shows the quantitative statistics of our research. Participants' average life expectancy is 77.4 years, which is consistent with Taiwan's average life expectancy (75.9 years for males and 82.5 years for females). The average annual household salary is approximately US $\$ 30,456$, and the maximum and minimum are US\$80,004 and US\$8,004, respectively. This shows that a significant difference in household salaries exists. The average net wealth and health expenditure of the households are respectively US\$66,625 and US $\$ 1,183 .{ }^{35}$ Bequest motivation measures how much money parents intend to leave to their children. The average bequest motivation is nearly US\$103,167. Therefore, bequest motivation seems to play an important role in households' financial decisions in Taiwan. Following Eisenhauer and Ventura's ${ }^{27}$ methodology, we calculate the average absolute risk aversion to be 0.0980 .

Based on the above statistics, we found that the ageing population is a serious problem in Taiwan because of prolonged lifespans and low fertility. An ageing population raises issues such as reduced tax revenue and labour supply shortages, with one of its most important

\footnotetext{
35 The average health expenditure in Taiwan is lower than in other countries. This could be because the Taiwan government provides National Health Insurance (NHI) to every citizen.
} 
Table 3 Descriptive statistics of participants $(N=100)$

\begin{tabular}{llc}
\hline & Variable & Percentage \\
\hline Gender & Male & 56 \\
& Female & 44 \\
Education & Junior high school or under & \\
& Senior high school & 2 \\
& University or college & 22 \\
& Master degree & 57 \\
Number of children & PhD degree & 18 \\
& & 1 \\
& None & \\
& One & 43 \\
Health status & Two & 19 \\
& Three & 31 \\
& Excellent & 7 \\
Risk attitude & Good & 25 \\
& Mediocre & 32 \\
& Ill & 38 \\
& Seriously ill & 4 \\
& & 1 \\
& Risk aversion & \\
& Risk neutral & 68 \\
& Risk lover & 28 \\
& & 4 \\
\hline
\end{tabular}

Table 4 Summary statistics

\begin{tabular}{|c|c|c|c|c|c|}
\hline & $N$ & Mean & Standard deviation & $\operatorname{Max}$ & Min \\
\hline Life expectancy & 100 & 77.4 & 8.1489 & 90 & 60 \\
\hline Salary & 100 & 30,456 & 12,840 & 80,004 & 8,004 \\
\hline Net wealth & 100 & 66,625 & 81,627 & 450,000 & 6,667 \\
\hline Health expenditure & 100 & 1,183 & 3,547 & 33,333 & 0 \\
\hline Bequest motivation & 100 & 103,167 & 95,895 & 333,333 & 0 \\
\hline Absolute risk aversion & 100 & 0.0980 & 0.1174 & 0.2 & -0.2 \\
\hline
\end{tabular}

(All monetary amounts are originally recorded in NT dollars. In Table 4, we convert the amount from NT dollars to U.S. dollars using an exchange rate of NT dollars to U.S. dollars of approximately 30 (NTD/USD=30)).

effects being a significant increase in pension and medical expenditure. Longevity risk influences people's consumption and investment decisions. However, increasing saving and reducing expenditure in response to longevity risk will impede economic growth. Furthermore, many studies argue that a change in the age structure of the population will be reflected in a change in investment needs and will cause price fluctuations in the capital market. ${ }^{36}$ Thus, the ageing issue and reducing the negative impact of longevity risk will remain a very important issue for Taiwan.

\footnotetext{
${ }^{36}$ Goyal (2004); Ang and Maddaloni (2005).
} 


\section{Regression model}

We investigate how households adjust their consumption and investment plans under longevity risk. In the second round of the experiment, households make their decisions in the absence of longevity risk, and in the third round, the households make their decisions with a longevity risk, but with other conditions remaining the same. We denote $C_{j}$, as the ratio of average consumption to average salary in the period $j(j=1,2,3)$. The period $j$ refers to specific periods, including the pre-retirement period $(j=1)$, the post-retirement period $(j=2)$ and the entire lifespan $(j=3) . \Delta C_{j}$, defined as Eq. (4), refers to the differences in the consumption-to-salary ratio in the second round and in the third round. We set the null hypothesis at $\Delta C_{j}=0$. If households adjust their consumption level in response to longevity risk significantly, the null hypothesis examined by the $t$-test will be rejected.

$$
\Delta C_{j}=\left(\frac{A C_{j}}{A S_{j}}\right)_{\text {with longevity }}-\left(\frac{A C_{j}}{A S_{j}}\right)_{\text {without longevity }} .
$$

Furthermore, we denote Stock $_{j}$ as referring to the average amount that households invest on risky assets within period $j$. Similarly, Riskless $s_{j}$ refers to the average amount that households invest on riskless assets within period $j$. We denote $I_{j}$ as the ratio of risky assets to the aggregate of riskless and risky assets in each period. $\Delta I_{j}$, defined as Eq. (5), refers to the change portion of risky assets with and without longevity risk. We set the null hypothesis at $\Delta I_{j}=0$. If households adjust their risky asset portion in response to longevity risk significantly, the null hypothesis subjected to the $t$-test will be rejected.

$$
\Delta I_{j}=\left(\frac{\text { Stock }_{j}}{\text { Riskless }_{j}+\text { Stock }_{j}}\right)_{\text {with longevity }}-\left(\frac{\text { Stock }_{j}}{\text { Riskless }_{j}+\text { Stock }_{j}}\right)_{\text {without longevity }} .
$$

Furthermore, in Model 1, we use the regression to investigate what factors will affect participants' consumption and investment decisions under longevity risk. The dependent variable in Eq. (6) is measured by the differences between consumption decisions in the second and the third rounds $\left(\Delta C_{j}\right)$. Similarly, the dependent variable in Eq. (7) is measured by the proportional change of risky asset (stock) in the second and the third round $\left(\Delta I_{j}\right)$. The independent variables include sex, age, salary, education, number of children, net wealth, life expectancy, health-care expenditure, bequest motivation and absolute risk aversion.

Model 1:

$$
\begin{aligned}
\Delta C_{i j}= & \alpha+\beta_{1} \text { Sex }_{i}+\beta_{2} \text { Age }_{i}+\beta_{3} S_{i}+\beta_{4} E d u_{i}+\beta_{5} \text { Chi }_{i}+\beta_{6} N W_{i} \\
& +\beta_{7} \text { Life }_{i}+\beta_{8} H E_{i}+\beta_{9} B_{i}+\beta_{10} A R A_{i}+\varepsilon_{c i j}, \\
\Delta I_{i j}= & \alpha+\beta_{1} \text { Sex }_{i}+\beta_{2} \text { Age }_{i}+\beta_{3} S_{i}+\beta_{4} E d u_{i}+\beta_{5} \text { Chi }_{i}+\beta_{6} N W_{i} \\
& +\beta_{7} \text { Life }_{i}+\beta_{8} H E_{i}+\beta_{9} B_{i}+\beta_{10} A R A_{i}+\varepsilon_{s i j} .
\end{aligned}
$$

\section{Empirical results}

Table 5 shows the $t$-test for the difference between consumption and investment decisions of the households when faced with or without longevity risk. We find that households reduce their consumption levels significantly during the pre-retirement, post-retirement and entire 
Table $5 T$-test for differences in consumption and investment decisions with and without a longevity risk

\begin{tabular}{|c|c|c|c|c|c|}
\hline \multicolumn{2}{|c|}{ Definition } & \multirow{2}{*}{$\frac{\text { Mean }}{-0.019}$} & \multirow{2}{*}{$\frac{S D}{0.061}$} & \multirow{2}{*}{$\frac{t \text {-value }}{-3.15}$} & \multirow{2}{*}{$\frac{p \text {-value }}{0.0021^{* * * *}}$} \\
\hline$\Delta C_{1}$ & $\left(\frac{A C_{1}}{A S_{1}}\right)_{\text {with longevity pre-retirement }}-\left(\frac{A C_{1}}{A S_{1}}\right)_{\text {without longevity pre-retirement }}$ & & & & \\
\hline$\Delta C_{2}$ & $\left(\frac{A C_{2}}{A S_{2}}\right)_{\text {with longevity post-retirement }}-\left(\frac{A C_{2}}{A S_{2}}\right)_{\text {without longevity post }- \text { retirement }}$ & -0.103 & 0.339 & -3.05 & $0.0030 * * *$ \\
\hline$\Delta C_{3}$ & $\left(\frac{A C_{3}}{A S_{3}}\right)_{\text {with longevity whole life }}-\left(\frac{A C_{3}}{A S_{3}}\right)_{\text {without longevity whole life }}$ & -0.061 & 0.178 & -3.45 & $0.0008^{* * * *}$ \\
\hline$\Delta I_{2}$ & $\left(\frac{\text { Stock }_{2}}{\text { Riskless }_{2}+\text { Stock }}\right)_{\text {with longevity post }- \text { retirement }}-\left(\frac{\text { Stock }_{2}}{\text { Riskless }_{2}+\text { Stock }_{2}}\right)_{\text {without longevity post - retirement }}$ & -0.021 & 0.152 & -1.37 & 0.1752 \\
\hline$\Delta I_{3}$ & $\left(\frac{\text { Stock }_{3}}{\text { Riskless }_{3}+\text { Stock }_{3}}\right)_{\text {with longevity whole life }}-\left(\frac{\text { Stock }_{3}}{\text { Riskless }_{3}+\text { Stock }_{3}}\right)_{\text {without longevity whole life }}$ & 0.014 & 0.095 & 1.44 & 0.1528 \\
\hline
\end{tabular}

Notes: (1) AC and AS refer to average consumption and average salary in period $j$, respectively.

(2) $* p<0.1 ; * *<0.05 ; * * p<0.01$.

lifespan period. Moreover, we discover that the mean and standard deviation for the postretirement period is larger than for the pre-retirement period. This indicates that households will reduce their expenditure to a greater extent in response to longevity after retirement. Figure 2 shows that the pattern of consumption plans is bell-shaped, which is consistent with the results of Modigliani's study. ${ }^{8,37}$ We also find that households reduce their expenditure over their entire lifespan in response to longevity risk. Furthermore, Figure 3 shows that the average saving ratio maintains at certain level. ${ }^{38}$ This could be because individuals have less income and decrease their expenditure simultaneously after they retire from their work. Our findings are consistent with previous studies, which conclude that households will reduce their expenditure and increase precautionary saving in order to mitigate longevity risk. ${ }^{4}$

For investment decisions, we find that before retirement, households reduce their percentage of risk-free assets and invest more money into risky assets in response to longevity risk. That is to say, people may take more risks in the expectation of higher returns to supplement the additional costs of a longer life expectancy. However, this phenomenon cannot be detected during the post-retirement period and the entire lifespan period. In Figure 4, we also discover that the ratio of risky assets in the face of longevity risk is higher than in the absence of longevity risk before retirement. However, people become more conservative during the post-retirement period even if they face longevity risk. Figure 4 also supports many previous findings that households gradually reduce their risky portfolio

37 The shape of consumption profiles is still a controversial issue that needs to be further investigated. One of the challenges to the life cycle model is the question of whether the empirical data really supports the fact that people save when they are young and reduce their saving when they grow old. Some papers have provided empirical support for the life-cycle hypothesis (Shorrocks, 1975; Modigliani, 1986). However, some empirical studies have found that the level of consumption is not reduced among the elderly (Mirer, 1979; Avery and Kennickell, 1991). Some studies have provided possible explanations for this phenomena, including bequest motivations, unexpected medical expenditures and longer life expectancy.

${ }^{38}$ In order to avoid different pension systems in Taiwan disturbing decision-making behaviour under longevity risk, we assume that there is no income after retirement. If we assume the income after retirement is the average income during the working period, the average saving profiles look like Figure 3. 




Figure 2. The average consumption amount with and without the longevity risk.

starting from the mid-life stage. ${ }^{39,40}$ Our empirical result is consistent with the conclusion of Yang and Huang ${ }^{14}$ that making a more aggressive asset allocation during the annuity accumulation period is a good way to mitigate the longevity risk for defined contribution (DC) pension plan members. Furthermore, Cocco and Gomes ${ }^{5}$ also document that individuals will benefit from investing in risky assets that can be used as a hedge against longevity risk.

Table 6 shows the relationship between households' demographic characteristics and their decisions. Nearly none of the demographic variables affects consumption decisions, apart from age and gender variables. We find that females will reduce their expenditure more than males in order to deal with longevity risk before retirement. Older-aged individuals also increase their saving during the post-retirement period and over their entire lifespan. These two demographic characteristics have long been hypothesised as affecting human behaviour in the literature. However, our study shows that demographic variables other than gender and age hardly explain consumption changes under longevity risk. For investment decisions, our empirical results also show that households with particular characteristics, such as including females, more children and with higher health-care expenditure, will increase the proportion of their risky assets to a lesser extent before retirement in response to longevity risk, compared with other households. After retirement, households with higher education,

${ }^{39}$ Campbell (2006); Fagereng (2009).

40 The shape of risky share profiles over an individual's lifespan is still a controversial issue. Many existing studies support a strong negative relationship between age and the percentage of risky assets in the individual's portfolio (Bodie and Crane, 1997; Heaton and Lucas, 2000; Bertaut and Starr McCluer, 2002). Furthermore, some studies also find the risky share to be hump-shaped over an individual's working lifetime (Hochguertel, 2003). Yoo (1994) finds that the ratio of risky asset to wealth increases over the working life and then declines after retirement. Our results support the shape of risky share profiles decreases with age. 


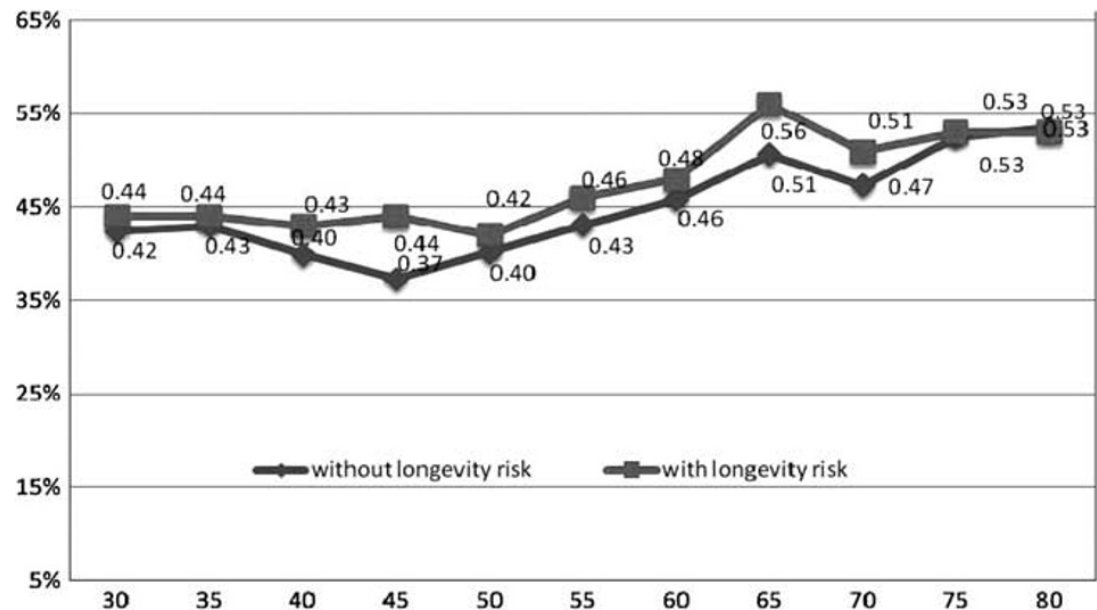

Figure 3. The average saving ratio with and without the longevity risk.

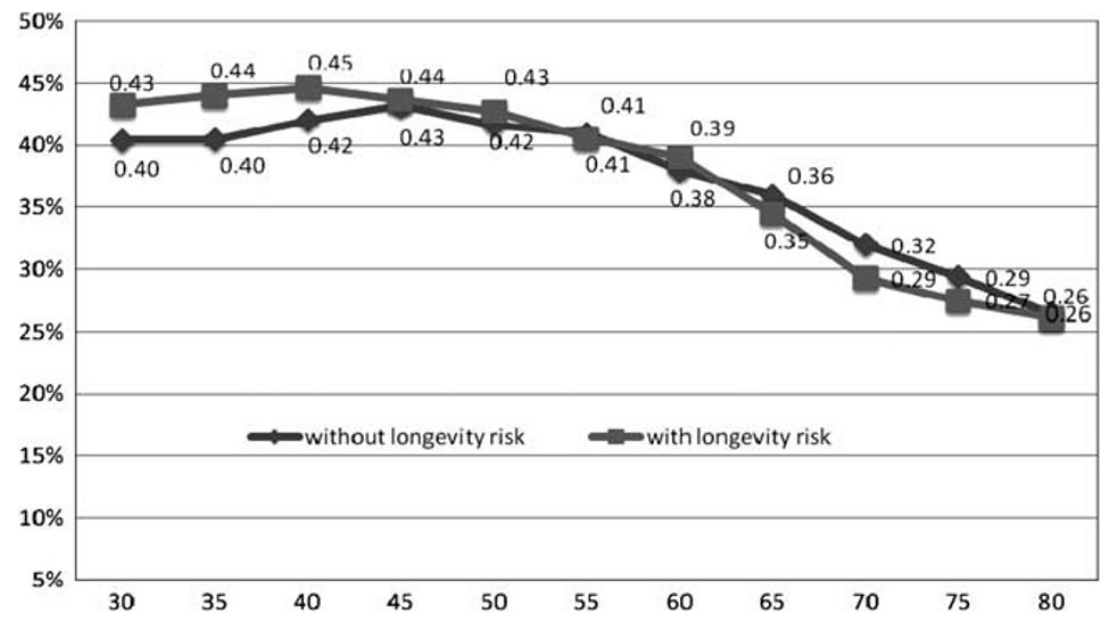

Figure 4. The average risky asset ratio with and without the longevity risk.

more children and a higher risk aversion will increase the proportion of their risky assets to a lesser extent compared with other households.

Over their entire lifespan, households with females, more children, higher health-care expenditure and higher risk aversion will increase the proportion of their risky asset holding in response to longevity risk, to a lesser extent than other participants. Our study shows that parents in Taiwan still regard children as an important factor in their investment decisions when they face longevity risk. The possible explanation for this is that parents with more children in Taiwan may expect to receive financial support from their children in the 
Table 6 The relationship between decisions and backgrounds of households $(N=100)$

\begin{tabular}{|c|c|c|c|c|c|c|}
\hline & \multicolumn{2}{|c|}{ Before retirement } & \multicolumn{2}{|c|}{ After retirement } & \multicolumn{2}{|c|}{ Whole life } \\
\hline & $\begin{array}{c}\text { Consumption } \\
\text { change } \Delta C_{1}\end{array}$ & $\begin{array}{c}\text { Stock holding } \\
\text { change } \Delta I_{1}\end{array}$ & $\begin{array}{c}\text { Consumption } \\
\text { change } \Delta C_{2}\end{array}$ & $\begin{array}{c}\text { Stock holding } \\
\text { change } \Delta \mathrm{I}_{2}\end{array}$ & $\begin{array}{c}\text { Consumption } \\
\text { change } \Delta C_{3}\end{array}$ & $\begin{array}{c}\text { Stock holding } \\
\text { change } \Delta I_{3}\end{array}$ \\
\hline \multirow[t]{2}{*}{ Intercept } & 0.1659 & $0.6203^{*}$ & -0.2392 & 0.9276 & -0.0367 & $0.6307 *$ \\
\hline & $(0.6354)$ & $(0.0684)$ & $(0.8704)$ & $(0.1331)$ & $(0.9626)$ & $(0.0780)$ \\
\hline \multirow{2}{*}{ Gender } & $0.0549 * *$ & $0.0636^{* * *}$ & 0.0399 & 0.0378 & 0.0474 & $0.0480 *$ \\
\hline & $(0.0260)$ & $(0.0078)$ & $(0.6952)$ & $(0.3767)$ & $(0.3844)$ & $(0.0539)$ \\
\hline \multirow{2}{*}{ Age } & -0.0015 & -0.0007 & $0.0302 * *$ & 0.0024 & $0.0144 * *$ & 0.0011 \\
\hline & $(0.6084)$ & $(0.7925)$ & $(0.0150)$ & $(0.6456)$ & $(0.0297)$ & $(0.6995)$ \\
\hline \multirow[t]{2}{*}{ Income } & 0.0080 & -0.0141 & 0.1352 & -0.0147 & 0.0716 & -0.0118 \\
\hline & $(0.7936)$ & $(0.6332)$ & $(0.2925)$ & $(0.7845)$ & $(0.2964)$ & $(0.7038)$ \\
\hline \multirow[t]{2}{*}{ Education } & -0.0167 & 0.0013 & 0.0110 & $-0.0676^{* *}$ & -0.0028 & -0.0184 \\
\hline & $(0.3730)$ & $(0.9414)$ & $(0.8873)$ & $(0.0405)$ & $(0.9459)$ & $(0.3287)$ \\
\hline \multirow[t]{2}{*}{ Children } & 0.0036 & $-0.0363 * * *$ & -0.0793 & $-0.0635^{* *}$ & -0.0378 & $-0.0439^{* * * *}$ \\
\hline & $(0.8004)$ & $(0.0100)$ & $(0.1898)$ & $(0.0132)$ & $(0.2407)$ & $(0.0033)$ \\
\hline \multirow[t]{2}{*}{ Net wealth } & 0.0049 & -0.01028 & -0.0793 & -0.0239 & -0.0372 & -0.0131 \\
\hline & $(0.6767)$ & $(0.3681)$ & $(0.1124)$ & $(0.2512)$ & $(0.1624)$ & $(0.2762)$ \\
\hline \multirow[t]{2}{*}{ Bequest } & -0.0187 & -0.0023 & -0.0511 & 0.0007 & -0.0349 & -0.0030 \\
\hline & $(0.2228)$ & $(0.8749)$ & $(0.4245)$ & (0.9806) & $(0.3078)$ & $(0.8462)$ \\
\hline \multirow[t]{2}{*}{ Health care } & 0.0050 & $-0.0241 * *$ & -0.0513 & -0.0219 & -0.0232 & $-0.0211 * *$ \\
\hline & $(0.6213)$ & $(0.0143)$ & $(0.2240)$ & $(0.2144)$ & $(0.3030)$ & $(0.0403)$ \\
\hline \multirow[t]{2}{*}{ Life expectancy } & -0.0054 & 0.0049 & 0.0034 & 0.0117 & -0.0010 & 0.0063 \\
\hline & $(0.4779)$ & $(0.5034)$ & $(0.9142)$ & $(0.3788)$ & $(0.9539)$ & $(0.4114)$ \\
\hline Absolute risk & 0.0568 & -0.08651 & 0.0500 & $-0.5120 * * *$ & 0.0534 & $-0.2288 * *$ \\
\hline aversion & $(0.6050)$ & $(0.4142)$ & $(0.9134)$ & $(0.0091)$ & $(0.8279)$ & $(0.0422)$ \\
\hline $\begin{array}{l}\text { Adjusted } \\
\qquad R \text {-square }\end{array}$ & 0.0121 & 0.1889 & 0.0586 & 0.0671 & 0.0514 & 0.1294 \\
\hline
\end{tabular}

Notes: (1) The number in ( ) indicates the $p$-value; (2) $0.1<p$-value $<0.05 \rightarrow^{*}, 0.01<p$-value $\leqq 0.05 \rightarrow * *$, $p$-value $\leqq 0.01 \rightarrow * * *$.

future, and consequently change the proportion of their risky assets to a lesser extent compared with other households without children. Moreover, we find that females are more conservative with financial risk-taking than males when they face longevity risk. This could be because women are more risk-averse than men. ${ }^{41}$ Furthermore, households with a higher ARA are more conservative with financial risk taking in response to longevity risk. Thus, households with females, more children and higher risk aversion may adjust their holding of risky assets discretely.

Furthermore, we also conduct a post-experimental survey in order to check robustly participant's decisions during our experiment. One question in our post-experimental survey is as follows: "Please rank the following types of behaviour that you will take in order to respond to longevity risk". For this purpose, five types of behavioural responses are listed, including reducing expenditure, increasing the proportion of risky assets, purchasing real

\footnotetext{
${ }^{41}$ Palsson (1996).
} 
estate, finding a part-time job to generate additional income and purchasing a commercial annuity. Nearly 40 and 26 per cent, respectively, of the participants make their priority choice the reduction of expenditures and the purchase of real estate. Approximately 17 per cent make their priority choice the increase in the proportion of risky assets. Based on our empirical results and interviews with the participants, we find that reducing expenditure is the priority choice when households face longevity risk. The second choice is increasing the portion of risky assets. ${ }^{42}$

\section{Discussions and implications}

The population ageing problem is an important issue that will affect most countries around world. The changes in population structure result from the low fertility and mortality. The structure will change the economic situation of countries because different age groups have distinct needs, expenditure habits and productive capacities. Thus, an investigation of how the longevity risk affects human behaviour with respect to consumption, saving and investment is very important in an ageing society. At the aggregate level, an increase in the percentage of elderly persons also has a significant impact on government spending. An inevitable consequence of the ageing problem is that, to maintain certain benefit levels, the government will increase expenditures on the public pension system. Then, because the probability of chronic disease increases with age, expenditure on the health-care system is also expected to increase sharply. Thus, the appropriate reform to control costs and reduce the burden on the public pension and health-care system is an important issue in an ageing society. Furthermore, in such a society, the country faces a decline in tax income and a decrease in the working age population, which may lead to a shrinking economy. The ageing population structure of countries also leads to some challenges, including debt, deficits and even deflation. Thus, policies such as the relaxation of immigration restrictions and the broadening of the tax base should be considered. An ageing population is also a serious problem in Taiwan because of its sharply increasing elderly population and low fertility rate. The ratio of the ageing population to total population in Taiwan is predicted to reach 20 per cent in 2026 and Taiwan's fertility rate, with an average of one child per woman in 2009 and 2010 has become the lowest in the world. Thus, investigating household consumption and investment decisions in response to longevity risk should be beneficial in providing some policy options for the Taiwan government.

Our empirical results indicate that when households face longevity risk, they will reduce their consumption regardless of the period (pre-retirement, post-retirement or entire lifespan period); that is, households will save more money in order to deal with longevity risk. If households cut down on their expenditure and save a larger portion of their income under longevity risk, such consumption retrenchment will impede economic growth. Thus, some policies that will help to mitigate the adverse impact of longevity risk could be considered. For example, governments can provide tax reduction incentives to encourage households to

${ }^{42}$ Purchasing real estate may be regarded as one kind of investment in risky assets. Because our experiment did not include any decisions relating to purchasing real estate, we might underestimate that the participants have the willingness to increase their risky asset holdings. 
buy more private health insurance and long-term care insurance, ${ }^{43}$ which will stabilise health-care expenditure under longevity risk. If households face less uncertainty about health-care expenditure in the future, they may be more willing to spend more money, even if they face longevity risk. Furthermore, we also observe that there is a significant drop in consumption between the pre-retirement period and the post-retirement period. In other words, people will prefer to reduce their consumption level after retirement because they have less income during this period. Based on our empirical results, the Taiwan government may raise the retirement age. This policy will not only encourage Taiwanese workers to remain in the labour force longer (thereby mitigating the shortage of labour in the ageing society), but also enable them to earn more income over their lifetime. The increase in lifetime income could enable Taiwanese workers to save less and consume more during their working years.

Since the ageing rate in Taiwan is projected to be faster than that of most developed countries, the financial burden of health care and the public pension system in Taiwan will inevitably increase in the future. In order to maintain some pension schemes, the Taiwan government will need to increase expenditure on subsidising the public pension system. The reform of the country's pension system, though difficult, appears to be inevitable in an ageing society. There are several possible ways that government can modify the pension systems to reduce costs, including increasing worker's contribution rates, reducing pension benefits and raising the retirement age. Furthermore, because many public pension schemes in Taiwan are in the form of defined benefit (DB) and pay-as-you-go plans, which place severe financial pressure on the government budget, the gradual transfer of some guaranteed pension plans to DC plans should be seriously contemplated by the Taiwan government. $^{44}$

Our empirical results also indicate that people hold more risky assets before retirement when they face longevity risk. In other words, households may take greater risks in order to exchange higher expected returns to supplement the additional costs of a longer life expectancy. However, although they receive more risk premiums from risky assets, they still cannot hedge against longevity risk, exactly because the risk premiums for these assets depend on other risk factors that are not attributable to the risk from the unexpected life extension. To hedge against longevity risk, the addition of mortality-based securities to the investment portfolio should be considered. Cowley and Cummins ${ }^{45}$ have documented that mortality risk is one of the drivers of the demand for insurance securitisation. Through mortality-based securitisation, the insurer can provide insurance to cover part of the longevity risk. If the capital market could create an asset such as survivor bonds or survivor

43 Taiwan's National Health Insurance (NHI) programme, which is well known worldwide, was launched in March 1995 with the goal to provide every citizen with equal access to comprehensive medical services regardless of their socio-economic status. Thus, Taiwanese have a lower incentive to purchase private (commercial) insurance and long-term care insurance.

44 The pension system in Taiwan may be divided into two broad categories: public and private. The public pensions system, which provides a basic safety net for the elderly, includes civil government employees' insurance, school staff insurance, military personnel insurance and the public service pension fund. Most of public pension systems in Taiwan are designed as defined benefit (DB) and pay-as-you-go plans. The private pension systems, which include labour insurance and a new labour pension fund, are designed as defined contribution (DC) plans for private sector employees.

${ }^{45}$ Cowley and Cummins (2005). 
swaps securitisation whose returns are highly correlated with the unexpected changes in life expectancy, individuals may hedge against the longevity risk more efficiently. Such mortality-based securitisation products would be beneficial for pension plan members because they can avoid taking unnecessary additional risks in preparing to fund their extended lives.

\section{Conclusion}

Because of the significant increase in average human life expectancy, individuals' decisionmaking behaviour in response to longevity risk has become an important topic of research. Although many studies have contributed to the modelling of an individual's decision-making behaviour in response to longevity risk, their theoretical results need to be further tested with empirical data. In this paper, we use empirical data to investigate how households adjust their consumption and investment plans under longevity risk. Two main conclusions emerge from our study. Firstly, we find that households reduce their expenditure in response to longevity risk. This finding is consistent with the conclusions of many theoretical studies that individuals will increase their precautionary saving when they face longevity risk. Households also increase the portion of their risky assets before retirement under longevity risk. Secondly, we find that households with females, more children, higher health expenditure and greater risk aversion plan to increase the proportion of their risky assets to a lesser extent in their whole life period under longevity risk, compared with other households. Longevity risk will become a serious problem for the Taiwan government in view of the increase in the ageing population. If people increase their saving and reduce their expenditure continuously in response to longevity risk, consumer retrenchment will impede economic growth. Therefore, the manner in which the Taiwan government avoids the shrinking of the consumer market and encourages increased household expenditure in an ageing society will become an important issue in the future.

With an ageing society, the financial burden of the pension system in Taiwan will inevitably increase in the future. Thus, the government should seriously consider possible ways to reduce the cost of the pension systems, including increasing workers' contribution rates, reducing pension benefits and raising the retirement age. Our empirical results support the conclusion that people increase the portion of their risky assets before retirement when they face longevity risk. However, the receipt of additional premiums from risky assets that are not attributable to unexpected life extension cannot be used to hedge against longevity risk effectively. If the government or the capital market could provide individuals with an asset whose returns are highly correlated with the unexpected changes in life expectancy (e.g. survivor bonds or survivor swap securitisation), such individuals may hedge their longevity risk more efficiently. These mortality-based securitisation products would be beneficial for pension plan members or households by enabling them to avoid taking unnecessary risk in preparing to fund their uncertain life extensions.

Nevertheless, there are still some limitations to this study. One is that it does not consider other ethnic groups and countries. Thus, our conclusions are only applicable to Taiwanese households. Further studies to investigate the same issue in other countries should be encouraged. Furthermore, while we only use the data collected in our experiment to undertake our empirical regression, the individuals could adjust their consumption and investment 
decisions in real-life situations. Although collecting survey data is time-consuming and expensive, the use of long-term panel data to investigate individuals' behaviour under longevity risk deserves further study. Another limitation of our paper is that the concept of longevity risk used only considers a higher expected lifetime. However, a number of existing studies refer to longevity risk as including not only a higher expected lifetime, but also the randomness around the trend in improvement of future mortality. Advanced empirical work to disentangle these two effects is therefore needed. Finally, individuals belonging to various pension plans may react differently in response to longevity risk. Individuals with DB plans may reduce their expenditure to a lesser extent than those with DC plans because they can receive a certain amount of pension after retirement. Therefore, further research to investigate whether people belonging to various pension systems make different consumption and investment decisions in response to longevity risk should be encouraged.

\section{Acknowledgements}

This article was presented at the Longevity Risk and Capital Market Solutions International Academic Seminar at National Chengchi University in Taipei, Taiwan, 16 May 2011. The authors would like to acknowledge helpful comments from the keynote speaker, Richard MacMinn. This article was also presented at the 7th International Longevity Risk and Capital Markets Solutions in Frankfurt, Germany, 9 September 2012. The authors would like to acknowledge helpful comments and feedback from the participants at this event, and especially the session chair, Anthony Webb and the discussant Thomas Post. The authors would like to thank the funding from the National Science Council of the Republic of China, Taiwan (Project number: 99-2410-H-032-043).

\section{References}

Ang, A. and Maddaloni, A. (2005) 'Do demographic changes affect risk premium? Evidence from international data', Journal of Business 78(1): 341-379.

Avery, R.B. and Kennickell, A.B. (1991) 'Household saving in the U.S.', Review of Income and Wealth 37(4): 409-430.

Barberis, N. (2000) 'Investing for the long run when returns are predictable', Journal of Finance 55(1): $225-264$.

Bertaut, C. and Starr-McCluer, M. (2002) 'Household Portfolio in the United States', in L. Guiso, M. Haliassos and T. Jappelli (eds) Household Portfolios, Cambridge: MIT Press.

Blake, D., Brockett, P., Cox, S. and MacMinn, R. (2006a) 'Longevity risk and capital market: The 2009-2010 update', North American Actuarial Journal 15(2): 141-149.

Blake, D. and Burrows, W. (2001) 'Survivor bonds: Helping to hedge mortality risk', Journal of Risk and Insurance 68(2): 339-348.

Blake, D., Cairns, A.J., Dowd, K. and MacMinn, R. (2006b) 'Longevity bonds: Financial engineering, valuation and hedging', The Journal of Risk and Insurance 73(4): 647-672.

Bodie, Z. and Crane, D.B. (1997) 'Personal investing: Advice, theory, and evidence', Financial Analysts Journal 53(6): 13-23.

Brown, J.R. and Orszag, P.R. (2006) 'The political economy of government-issued longevity bonds', Journal of Risk and Insurance 73(4): 611-631.

Campbell, J. (2006) 'Household finance', The Journal of Finance 61(4): 1553-1604.

Campbell, J. and Viceira, L. (1999) 'Consumption and portfolio decisions when expected returns are time varying', Quarterly Journal of Economics 114(2): 433-495.

Chen, H. and Cummins, J.D. (2010) 'Longevity bond premiums: The extreme value approach and risk cubic pricing', Insurance: Mathematics and Economics 46(1): 150-161.

Cheng, Y. and Han, X. (2011) 'Does large volatility help?-Stochastic population forecasting technology in explaining real estate price process', Journal of Population Economics 26(1): 323-356. 
822

Cocco, J.F. and Gomes, F.J. (2009) 'Longevity risk, retirement savings, and financial innovation', Journal of Financial Economics 103(3): 507-529.

Cowley, A. and Cummins, J.D. (2005) 'Securitization of life insurance assets and liabilities', The Journal of Risk and Insurance 72(2): 193-226.

Dawson, P., Blake, D., Cairns, G. and Dowd, K. (2010) 'Survivor derivatives: A consistent pricing framework', The Journal of Risk and Insurance 77(3): 579-596.

De Nardi, M., French, E. and Jones, J.B. (2009) 'Life expectancy and old age savings', American Economic Review 99(2): 110-115.

Deng, Y., Brockett, P. and MacMinn, R. (2012) 'Longevity/mortality risk modeling and securities pricing', Journal of Risk and Insurance 79(3): 697-721.

Dowd, K., Blake, D., Cairn, G. and Dawson, P. (2006) 'Survivor swaps', Journal of Risk \& Insurance 73(4): 1-17.

Dynan, K. (1993) Habit formation in consumer preferences: Evidence from panel data, Board of Governors of the Federal Reserve System, no.143.

Eisenhauer, J.G. and Ventura, L. (2003) 'Survey measures of risk aversion and prudence', Applied Economics 35(13): 1477-1484.

Fagereng, A. (2009) Household Portfolio Allocation and Age, Oslo: European University Institute, Florence $\&$ Statistics Norway.

Fuhrer, J. and Klein, W. (2006) 'Risky habits: On risk sharing, habit formation, and interpretation of international consumption correlations', Review of International Economics 14(4): 722-740.

Goyal, A. (2004) 'Demographics, stock market flows, and stock returns', Journal of Financial and Quantitative Analysis 39(1): 115-142.

Heaton, J. and Lucas, D. (2000) 'Portfolio choice and asset prices: The importance of entrepreneurial risk', Journal of Finance 55(3): 1163-1198.

Hochguertel, S. (2003) 'Precautionary motives and portfolio decisions', Journal of Applied Econometrics 18(1): 61-77.

Kandel, S. and Stambaugh, R. (1996) 'On the predictability of stock returns: An asset allocation perspective', Journal of Finance 51(2): 385-424.

Kogure, A. and Kurachi, Y. (2010) 'A Bayesian approach to pricing longevity risk based on risk-neutral predictive distributions', Insurance: Mathematics and Economics 46(1): 162-172.

MacMinn, R., Brockett, P. and Blake, D. (2006) 'Longevity risk and capital markets', The Journal of Risk and Insurance 73(4): 551-557.

Menoncin, F. (2008) 'The role of longevity bonds in optimal portfolios', Insurance: Mathematics and Economics 42(1): 343-358.

Merton, R. (1969) 'Lifetime portfolio selection under uncertainty: The continuous-time case', Review of Economics and Statistics 51(3): 247-257.

Milevsky, M.A., Moore, K.S. and Young, V.R. (2006) 'Asset allocation and annuity-purchase strategies to minimize the probability of financial ruin', Mathematical Finance 16(4): 647-671.

Mirer, T.W. (1979) 'The wealth-age relation among the aged', American Economic Review 69(3): $435-443$.

Modigliani, F. (1986) 'Life cycle, individual thrift, and the wealth of nations', American Economic Review 76(3): 297-313.

Modigliani, F. and Ando, A. (1957) 'Tests of the life-cycle hypothesis of savings: Comments and suggestions', Bulletin of the Oxford Institute of Statistics 19(2): 99-124.

Modigliani, F. and Brumberg, R. (1954) 'Utility Analysis and the Consumption Function: An Interpretation of Cross-section Data', in K.K. Kurihara (ed.) Post-Keynesian Economics, New Brunswick, NJ: Rutgers University Press, pp. 388-436.

Mossin, J. (1968) 'Optimal multi-period portfolio policies', Journal of Business 41(2): 205-225.

Oeppen, J. and Vaupel, J.W. (2002) 'Broken limits to life expectancy', Science 296(5570): 1029-1031.

Palsson, A.M. (1996) 'Does the degree of relative risk aversion vary with household characteristics?' Journal of Economic Psychology 17(6): 771-787.

Post, T. (2012) 'Individual welfare gains from deferred life-annuities under stochastic mortality', Asian-Pacific Journal of Risk and Insurance 6(2): 2.

Post, T. and Hanewald, K. (2013) 'Longevity risk, subjective survival expectations, and individual saving behavior', Journal of Economic Behavior and Organization 86(1): 200-220.

Samuelson, P.A. (1969) 'Lifetime portfolio selection by dynamic stochastic programming', Review of Economics and Statistics 51(3): 239-246. 
Schulze, R.N. and Post, T. (2010) 'Individual annuity demand under aggregate mortality risk', Journal of Risk and Insurance 77(2): 423-449.

Shorrocks, A.F. (1975) 'The age-wealth relationship: A cross-section and cohort analysis', Review of Economics and Statistics 57(2): 155-163.

Stallard, E. (2006) 'Demographic issues in longevity risk', Journal of Risk and Insurance 73(4): 575-609.

Stevens, R. (2010) Annuity decisions with systematic longevity risk, working paper, Tilburg University.

Taiwan Council of Economic Planning and Development (2008) Population Projection 2008-2056 in Taiwan ROC, pp. 9-11.

Vaupel, J.W. (1986) 'How change in age-specific mortality affects life expectancy', Population Studies 40(1): 147-157.

Yang, S.S. and Huang, H.C. (2009) 'The impact of longevity risk on the optimal contribution rate and asset allocation for defined contribution pension plans', The Geneva Papers on Risk and Insurance-Issues and Practice 34(4): 660-681.

Yogo, M. (2012) Portfolio choice in retirement: Health risk and the demand for annuities, housing, and risky assets, Boston College Center for Retirement Research working paper No. 2009-3.

Yoo, P.S. (1994) Age, dependent portfolio selection, Federal Reserve Bank of Saint Louis, working paper No. 94-003 A.

\section{About the Authors}

Joseph J. Tien is Assistant Professor in the Department of Insurance at Tamkang University, Taiwan. He teaches insurance, asset and liability management, and corporate finance. Dr. Tien's research focuses on the ageing society, health insurance programmes and insurance finance. His research has been published in journals such as The Geneva Papers on Risk and Insurance-Issue and Practice, Journal of Risk Management, Applied Economics, Health Policy and Empirical Economics Letter.

Jerry C.Y. Miao is Professor in the Department of Insurance at Tamkang University, Taiwan. He teaches investment, insurance finance and pension fund management. Professor Miao's research usually focuses on the areas of population structure, pension fund management and insurance finance. His research has been published in journals such as Insurance: Mathematics and Economics, Asia-Pacific Journal of Risk and Insurance, and Journal of Empirical Finance. 